of papers published in the decades of the Geological Survey of the United Kingdom are among the most valuable of the works issued by that body. An excellent man of business, Sir Philip took an active part in the administration of the British Museum, the London University, the Geological Society, and other institutions for the promotion of science. All who knew him willmiss the kindly face and cheerful manners which distinguished him. Only two days before his death he was in his place in Parliament, but a chill caught during the lately prevalent east winds proved rapidly fatal. At the last meeting of the Geological Society the vice-president, Mr. J. Whitaker Hulke, F.R.S., made announcement of his death, and the sudden and unexpected tidings concerning one who was so widely known and so universally respected cast a sad gloom over the proceedings of the evening.

A correspondent sends us the following additional note on the late Sir Philip Egerton :-

The knowledge of the extinct species of fishes is one of the latest additions to palæontology, and the creator of this department of the science, Louis Agassiz, found the richest materials for his great work in the British Isles. In their acquisition he was greatly aided by Lord Cole, now Earl of Enniskillen, and by Sir Philip de Malpas Grey Egerton, Bart., M.P. Their gatherings resulted in most complete collections of fossil fishes, and science is much indebted to the catalogues drawn up and published by Sir P. Egerton of that preserved at Oulton Park. Besides the species named by Agassiz this collection includes many which have been subsequently determined and described by Sir P. Egerton, whose name will be ever associated with that of Agassiz in palichthyology. In his public career Sir Philip Egerton has been distinguished by his unremitting attention to his parliamentary duties in the long period since his election in 1830 . The British Museum sustains a severe loss in a Trustee, elected in $185 \mathrm{I}$, whose scientific knowledge, sound judgment, and administrative ability were of the greatest value, especially to the Natural History Departments. Sir Philip's last attendance at the Board was but a few days-apparently in his usual good health-before his lamented death.

\section{THE SCIENTIFIC PRINCIPLES INVOLVED IN} ELECTRIC LIGHTING

FOUR Cantor Lectures on this interesting subject have just been delivered at the Society of Arts by Prof. W. Grylls Adams, F.R.S. ; the lectures will be published in full in the Journal of the Society of Arts, but we are able to give an abstract of them by Prof. Adams. In the first lecture, the discoveries of Ersted, Ampère, Arago, and the early discoveries of Faraday on magnetic and current induction were considered in their relation to the principles of conservation and transformation of energy.

Lecture I.-Prof. Adams began by stating and illustrating the fact that important discoveries, after they are made, often pass through a stage of neglect or a stage of quiet development, then enter on the practical stage, when new facts and new inventions follow with great rapidity. The potential energy of the discoverer is transformed into energy of action in many directions with more or less efficiency, according to the retarding state of the medium through which that action takes place.

Electrical science has passed through these stages, whether we regard telegraphy from the work of Sir Francis Ronalds in 1816 , who said, "Let us have electrical conversazione offices communicating with each other all over the kingdom," down to the establishment of telephonic exchanges, or whether we consider electric lighting from the grand experiment of Sir Humphry Davy in 1813 with a battery of 2000 cells, down to the latest results obtained by means of the most recent magneto- or dynamo-electric machines.

In the year I8I9 Ersted observed the action of a current of electricity on a suspended magnetic needle, and in the year 1820 Ampère studied the laws of their mutual actions, and propounded his celebrated theory of magnets and of terrestrial magnetism, making magnetism the resultant action of electric currents. In the same year Arago discovered the magnetisation produced by electric currents, laying the foundation of the subject of electro-magnetism.

The discoveries of EErsted, Ampère, and Arago were fully illustrated by experiments, and their connection with one another explained. In the same year, I820, Schweigger invented the galvanometer, and in $1827 \mathrm{Ohm}$ deduced his simple theory of the action of batteries from the principle of Volta.

'The relation of the experiments of CErsted, Ampère, and Arago to the principle of conservation of energy was then fully considered. Considering Ampère's experiment of the motion of wires towards one another when like parallel currents are flowing in them, it was shown that the currents must be diminished whilst they are actually approaching, and increased whilst they are separating, and so by supposing one of the original currents very small, the relation between Ampère's results and the induction of a current by moving a wire in the neighbourhood of another current was deduced.

The laws of induced currents were then explained and illustrated by some of the early experiments of Faraday, who discovered the induction of electric currents by magnets in $183 \mathrm{I}$.

"In his first series of papers to the Royal Society entitled-(1) On the Induction of Electric Currents, (2) On the Evolution of Electricity from Magnetism, (3) On a New Electrical Condition of Matter, (4) On Arago's Magnetic Phenomena, Faraday unfolds step by step the laws of the induced current in a helix of wire $B$, placed near to another helix A, carrying a voltaic current.

"That as long as a steady current was maintained in A there was no current induced in B; that on making contact in $\mathrm{A}$ or on approaching the wires there was a momentary inverse current in $\mathrm{B}$, and on breaking contact in A or on separating the wires, there was a direct induced current in B. That as this current was of the nature of an electric wave like the shock of a Leyden jar, it might magnetise a steel needle, although it produced slight effect on a galvanometer, and how this expectation was confirmed, and that the needle was magnetised opposite ways on making and on breaking contact." Then in his evolution of electricity from magnetism he gives an account of the greatly increased effects on introducing soft iron cores into his helices of wire, and shows that similar effects are obtained by using ordinary magnets in place of a helix carrying a battery current round an iron core, i.e., in place of an electromagnet. He then describes the experiment of introducing a magnet into a coil of wire, and shows that the same current is obtained whether the marked end of the magnet be introduced at one end of the coil or the unmarked end introduced at the other, and that a current is produced in the opposite direction to the former on withdrawing the magnet from either end. Then after describing the method of producing his induction spark and also muscular contractions of a frog by means of a loadstone and coil, and remarking that the intensity of the effect produced depends upon the rate of separation of the coil from the poles of the loadstone, he concludes this section thus: An agent which is conducted along metallic wires in the manner described; which, whilst so passing, possesses the peculiar magnetic action and force of a current of electricity; which can agitate and convulse the limbs of a frog, and which finally can produce a spark, can only be electricity. 
Faraday also observed the difference of time between induction by a battery current in a coil, which is instantaneous, and induction by a magnet, which requires an interval of time to get up to its full value; and accounted for this retardation by supposing that there is a redistribution of the Amperian currents in the iron itself, so that the magnet requires time to rise to its full power.

Little did Faraday dream of the rapid development and the marvellous results which were to flow from his experiments when, fifty years ago, he established the laws of magnetic and current induction, being stimulated (as he says) to investigate experimentally the inductive effects of electric currents with the view of elucidating Ampère's beautiful theory of magnetism, and in the hope of obtaining electricity from ordinary magnetism.

Lecture II. - It was shown in the last lecture that a circular current or a current in a coil of wire acted as a magnet, one face of the coil, in which, as we look at it, the current appears to go contrary to the hands of a watch, corresponding to the marked pole or the pole of a magnet which points to the north, and the opposite face of the coil corresponding to that pole of the magnet which points to the south. Each of the Amperian circular currents in the separate molecules of a magnet is equivalent to a fine magnet with poles of the same magnetic strength as the current, and occupying the same position, and the collection of Amperian currents will have the same magnetic effect as the bundle of small magnets, each of which gives the direction of the magnetic force at the point. These separate fine magnets may be regarded as Faraday's lines of force, and the number of them issuing from a magnetic pole will be a measure of the strength of the magnet. The magnetic field of the magnet is any portion of space to which the influence of the magnet extends. The current which will be produced by the motion of a conducting wire in the magnetic field will be proportional to the strength of the magnetic field, i.e. proportional to the number of lines of force cut by the conductor; so that the current produced in each half turn of a coil of wire revolving on an axis is proportional to the number of lines of force cut by the coil during its rotation, so that the total current from the coil will be proportional to the number of lines of force multiplied by the number of times the wire is repeated in the coil. In the case of a coil of wire rotating in the field of a magnet, if the axis of rotation is parallel to the lines of force no current is produced, but as the axis of rotation is turned more and more nearly at right angles to the lines of force the current in the coil is increased. Taking the earth for our magnet, when the axis of rotation is perpendicular to the lines of force and still in the magnetic meridian, the current in that half of the coil which is moving from west to east will be from north to south, and the current in the other half of the coil which is moving from east to west will be from south to north, so that in the whole coil we get during every half turn an all-round current in one direction in the coil. The direction of the current in the coil, as we look at it from the east, is the same as the direction of rotation of the coil as we look at it from the north. The direction of the current in the coil is alternately in opposite directions for every half turn, but a continuous current may be obtained from it by reversing the connections with the ends of the coil by a commutator at the same instant as the currents are reversed in the coil.

These are the principles of all magneto-electric machines. The distribution of lines of force in the rnagnetic field of currents and of magnets is well shown by projecting some of Prof. S. P. Thompson's transparencies, which show the magnetic effects resulting from the mutual action of currents and magnets on one another.

After the discovery by Faraday, in 1831 , of the method of producing a current of electricity by the sudden removal of a coil of wire from the pole of a magnet, the laws of these currents were being developed, but for twenty years no attempt was made to apply them for the purposes of electric lighting. Voltaic batteries were being improved, and the more constant batteries of Daniell, of Grove, and of Bunsen were discovered, and these were the sources of electricity employed to produce the more powerful currents of electricity. In this country forty or fifty cells of Grove have given us the electric light for optical experiments in our laboratories, and the light was kept steadily in the same position by the elaborate arrangements of wheel-work and electromagnets devised by Staite in 1847 and by Foucault, which have reached very great perfection in the hands of Duboscq. In the Duboscq lamp the current passes always in the same direction, and the positive carbon becomes hollowed out, and burns away about twice as fast as the negative carbon, which becomes pointed. The carbons are moved towards one another by means of a drum carrying two wheels, whose diameters are as 2 to $I$, which move two racks which bring the carbons together This lamp is especially adapted for projection on a screen, and we may study the forms of the carbons by projecting them, and also study the kind of light given out by the vapours of metals burning in the arc; if we burn silver in the arc we shall see that it is rich in the violet or chemical rays, which points to the reason why the salts of silver are so much used in photography.

Even with constant batteries there is great variation in the steadiness of the electric light, but much more is this the case when the current of electricity is obtained by the motion of a coil of wire in a magnetic field, for every alteration in the resistance in the circuit reacts on the machine producing the current so as to increase the disturbance. Hence regulators are necessary in order to control the current, so as to keep the light constant. In electric lighting regulators may act on the electric lamps themselves so as to give a steady current between the carbons by keeping them the same distance apart, or regulators may be used in another part of the circuit to control the current automatically by causing it to introduce extra resistance when the current increases, and to diminish the resistance when the current diminishes.

Various methods of regulating the current, including those employed by Siemens, Lane Fox, and Edison, were then described. In order to find the yield or effective work of batteries or magneto-electric machines and their efficiency, measurements of the current and of the work done by the current must be made.

There are four principal methods of measuring electric currents :-

I. The galvanometer method, by which with a galvanometer of small resistance a very small fraction of the current is measured, and any error of observation is multiplied in estimating the total current flowing.

2. The heat method, in which the current is measured by the heat developed by the current in a given resistance in the circuit according to Joule's law, that the heat is proportional to the square of the strength of current.

3. The electrometer or potentiometer method, in which the difference of potential between two points in the circuit with a given resistance between them is directly measured and the current deduced from Ohm's law.

In using Thomson's quadrant electrometer for strong currents, the needle and one pair of quadrants should be connected together, so that the deviation is then proportional to the square of the difference of potential, and this method is applicable for continuous currents and also for alternate currents. By means of two electrometers in different parts of the circuit the current and also the work done by it may be at once measured. If, for instance, one of the electrometers be connected with the two carbons, the difference of potential and work done between the carbons may be determined. By such measurements it has been found that there is an electro- 
motive force of 30 or even 40 volts between the carbons in the electric arc, but that the actual resistance of the arc is small.

4. The electro-dynamometer method, the best method fitted for ready measurement, in which the current in one coil is attracted by the same current flowing in another coil, and the attraction is balanced by a spring as in Siemens's electro-dynamometer, or by weights as in Trowbridge's electro-dynamometer. A beautifully-made instrument by Elliott and Co. was exhibited, in which the coils are thick copper bands, fixed coils being placed on each side like the coils of a tangent galvanometer, the suspended coil being placed between them in place of the magnet of the galvanometer. This instrument is especially useful for the measurement of very large currents in absolute measure.

The remainder of the second lecture was devoted to the consideration of the efficiency of batteries or of mag. neto-electric machines when employed as motors to do work by means of electricity, and it was shown that the greatest amount of effective work is produced when onehalf the energy of the battery or current-generating machine is converted into useful work in the electric circuit. Numerous experiments were made with Clarke's and other magneto-electric machines to show that by the same machine work may be produced by sending a battery current through it, causing motion of the armature carrying the current in accordance with Ampère's laws, or a current of electricity may be generated by turning the armature, i.e. by doing work upon the machine, so that a magneto-machine is a reversible engine. A small magneto-machine with a Siemens armature was made to work a pump, or when turned by hand produced a current of electricity. Also a battery current in a Gramme ring in front of the poles of a Jamin magnet caused rotation of the ring and turned the heavy driving-wheel of the machine, and on removing the battery and turning the driving-wheel by hand, a current of electricity was produced which caused a piece of platinum wire to glow. Also a Tisley's hand dynamo-machine was employed either to heat a long piece of platinum wire or to drive another magneto-electric machine, so producing a secondary current capable of heating a considerable length of platinum wire.

(To be continued.)

THE FRENCH ASSOCIATION FOR THE ADVANCEMENT OF SCIENCE AT ALGIERS

\section{Algiers, April I4}

THE number of members enrolled for the present Congress is much larger than might have been expected when we consider the length of the journey. To a Parisian member this is such as would be experienced by a Londoner if our British Association met in Gibraltar. Yet more than 1500 names are on the list. Few of these are familiar to us. There appear to be an unusual number of doctors and professors of anatomy and physiology, and of civil engineers. We fear we must also confess that a great many people possessing little or no interest in science, who will not be present at a single sectional meeting, have joined the Association for the sake of seeing Algiers. The general character of the meeting appears to be that of a great excursion. There are only five days partially devoted to work; while the banquets, balls, fêtes, courses, and "fantasias" are rapidly multiplying.

On arriving in Paris we were told that the steamer which was to have conveyed us to Algiers had been requisitioned by the Government for the transport of troops to Tunis; but the Company determined at last to take both soldiers and savants, and the result was of course an overcrowded boat and excessive discomfort. With accommodation for fifty first-class passengers no less than one hundred and twenty-nine were crowded into the vessel, and had the voyage been anything but of the smoothest, it would have been most wretched. As it was it was bad enough ; the food was insufficient in quantity and detestable in quality, and passengers were glad to find six feet of floor to sleep upon. In Algiers itself the hotels are quite full, and the salons will be used as dormitories.

The Congress will be opened to-day by the inaugural address of $M$. Chauveau, which is to be given in the theatre at three o'clock, after which the members will remain and resolve themselves into a general committee to discuss the creation of a sixteenth section relating to pedagogy; afterwards the secretaries of sections will meet to arrange their proceedings, and at 9 p.m. the members will be received by the Municipality at the Hotel de Ville. The general programme for the rest of the week is as follows :-

Friday, April 1 5.-Sectional meetings in the forenoon; general meeting at 2 p.m.; conference at half-past 8.

Saturday.-Sectional meetings in the morning; visit to the Algerian Exhibition in the afternoon; Arab fête, and a soirée given by the Municipality.

Sunday.- "Courses et fantasia."

Monday.-Sectional meetings in the morning; a procession through the town in the afternoon, and an Arab fête in the evening.

Tuesday.-Sectional meetings; general concluding meeting ; in the evening a ball given by the Governor.

On Wednesday the excursions commence; they are toth general and sectional, and the longest lasts for a fortnight.

A complete list of the papers to be read has not yet appeared, but in the list already published we do not note anything of special interest.

English science is represented by Dr. G. H. Gladstone and Mr. Siemens, who will both read papers.

The Association has presented to each member a work in two volumes entitled "Notices scientifiques, historiques, et economiques sur l'Alger et Algérie."

\section{April I 5}

The theatre was well filled yesterday afternoon to hear the address of the president, M. Chauveau, who is Professor of Physiology in the Lyons Veterinary College. His discourse was of a far too technical character to be of interest to the majority of his audience, and dealt principally with the germ theory and Pasteur's theory of fermentation. It was read throughout without the least attempt at oratory, and it contained various political allusions which were much applauded. In the evening the members were entertained by the Municipality, and the town was illuminated. The real work of the Association commenced this morning, when the sections met at hours varying from eight to ten o'clock. We fear that the number of papers is small, and that the Association does not represent French science at all completely. In the Physical Section, for example, the names of only two authors of papers appear to-day-MM. Brillouin and Crova. At 9 a.m., when the section was announced to meet, no one was present. Shortly afterwards the secretary arrived, but an hour later the section had not met. The average number of the audience at the sections which had already met did not at this time exceed ten.

Among the more interesting papers announced for today are the following:-M. Marcheray, on Telephonic Communication in large towns; $M$. Tacchini, on the Observatories of Etna and of Chimona; M. Thoulet, on the Employment of the Microscope in Chemical and Physical Researches connected with Mineralogy; M. Prungrueber, on 300 Anthropological Observations on the Kabyles of the Djurdjura Mountains.

The Medical and Agronomical Sections have plenty of communications. The new section of Pedagogy has been established under the honorary presidency of $M$. 